\title{
RANCHO DE RESISTÊNCIA
}

\section{Daniel dos Santos Fernandes ${ }^{1}$}

A costa nordeste do Pará teve como um dos fatores de presença humana a atividade pesqueira. Com a possibilidade de utilização desse espaço para a construção de portos de escoamento de produtos, alguns grupos de pescadores confrontaram-se com transformações que aconteceram de maneira muito rápida. Desta forma, pescadores artesanais da microrregião do Salgado no Pará começaram a perder seus territórios de pesca e a sofrerem impactos sociais causados, entre eles, pelo projeto de construção do Terminal Marítimo Offshore do Espadarte. Este empreendimento impacta de modo direto e/ou indireto sobre os recursos naturais existentes na área, bem como sobre as formas tradicionais de organização social dos pescadores, consequentemente sobre suas realidades simbólicas e valorativas.

Este é o caso dos pescadores artesanais que tem seus ranchos no município de Curaçá, no Pará. Neste ensaio apresento o modo de ocupação de uma destas famílias, a partir de sua habitação. Este grupo de famílias vive em ranchos de pesca, tipo de habitação anteriormente só ocupada na época de atividades pesqueiras mais intensa, mudando muitas vezes a dinâmica de tarefas comuns nas famílias como a divisão de atividades por gênero. A rotina tem agora outra dinâmica. Atividades que antes eram divididas entre os membros da família, são agora realizadas por todos. Por outro lado, novas tarefas emergem. Como uma espécie de estratégia de resistência para garantir seus espaços, a exemplo da família de Zé Gregório e de Dona Natividade. Em especial Dona Natividade, além de ser responsável pela alimentação, passa a ter também a incumbência de segurança da área toda vez que seu Zé Gregório está ausente. São estratégias que buscam manter uma ocupação que vai muito além de

Entre as comunidades de ribeirinhos da Amazônia e os pescadores artesanais do litoral, existem formas de apropriação articuladas em função de seus usos, significados e conhecimentos das águas. No caso desses últimos, o usufruto coletivo de áreas determinadas estendia-se para além da terra para incluir 'territórios marinhos'. (Little, 2002, p. 9)

\footnotetext{
${ }^{1}$ Faculdades Integradas Ipiranga, Brasil.
} 
Uma prática, uma espécie de garantia que começou a reforçar as relações parentais contra a entrada de uma cultura exógena que poderá modificar a estrutura ocupacional das populações pesqueiras da costa de Curuçá.

Trago na sequência uma narrativa fotográfica que relata minha experiência etnográfica desenvolvida em abril de 2011, na Praia da Romana, no município de Curaçá (PA). Na ocasião usamos uma câmera Sony DCR-PJ6.

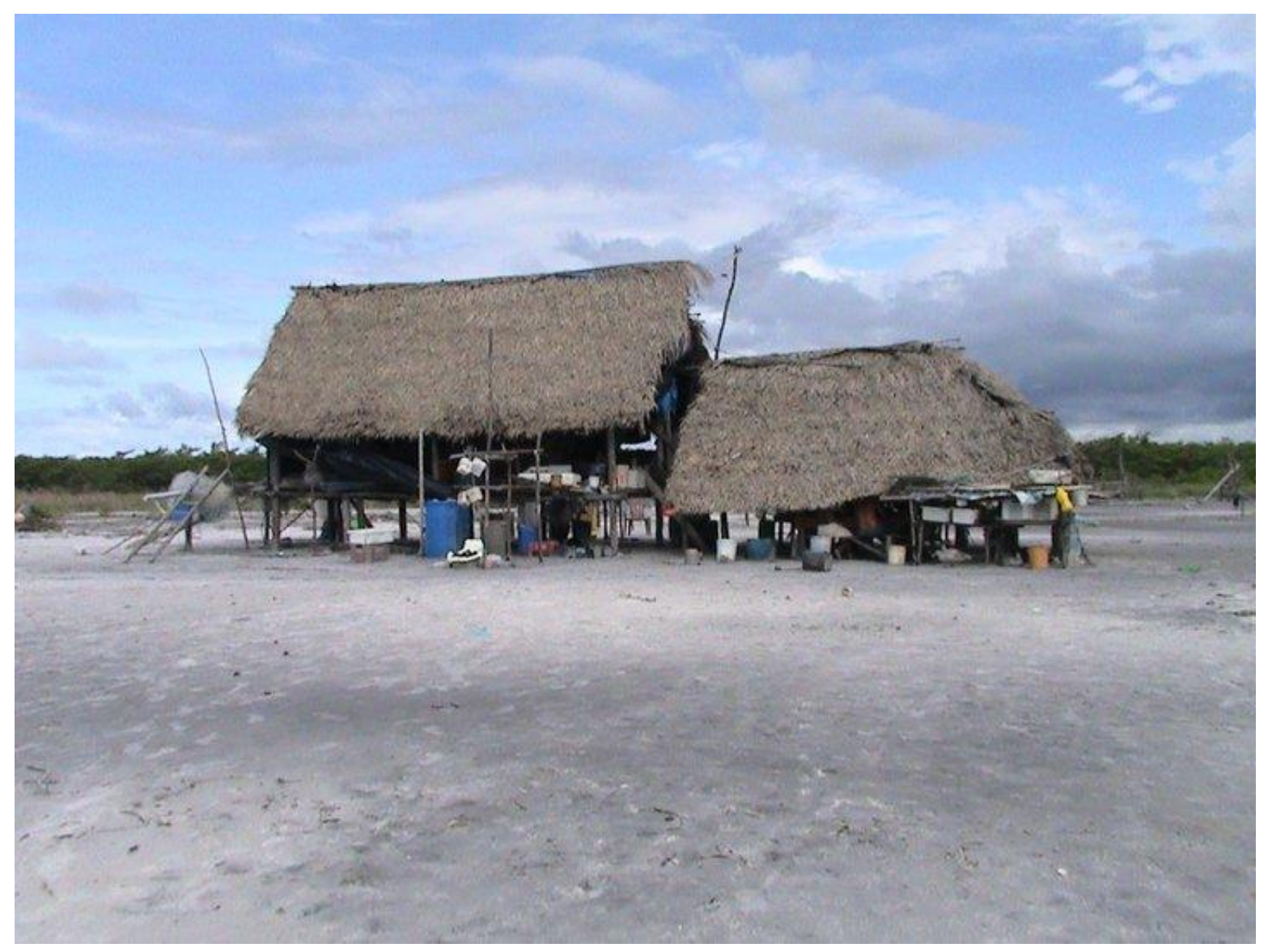

Figura 1: Chegada ao rancho da família do Zé Gregório. 


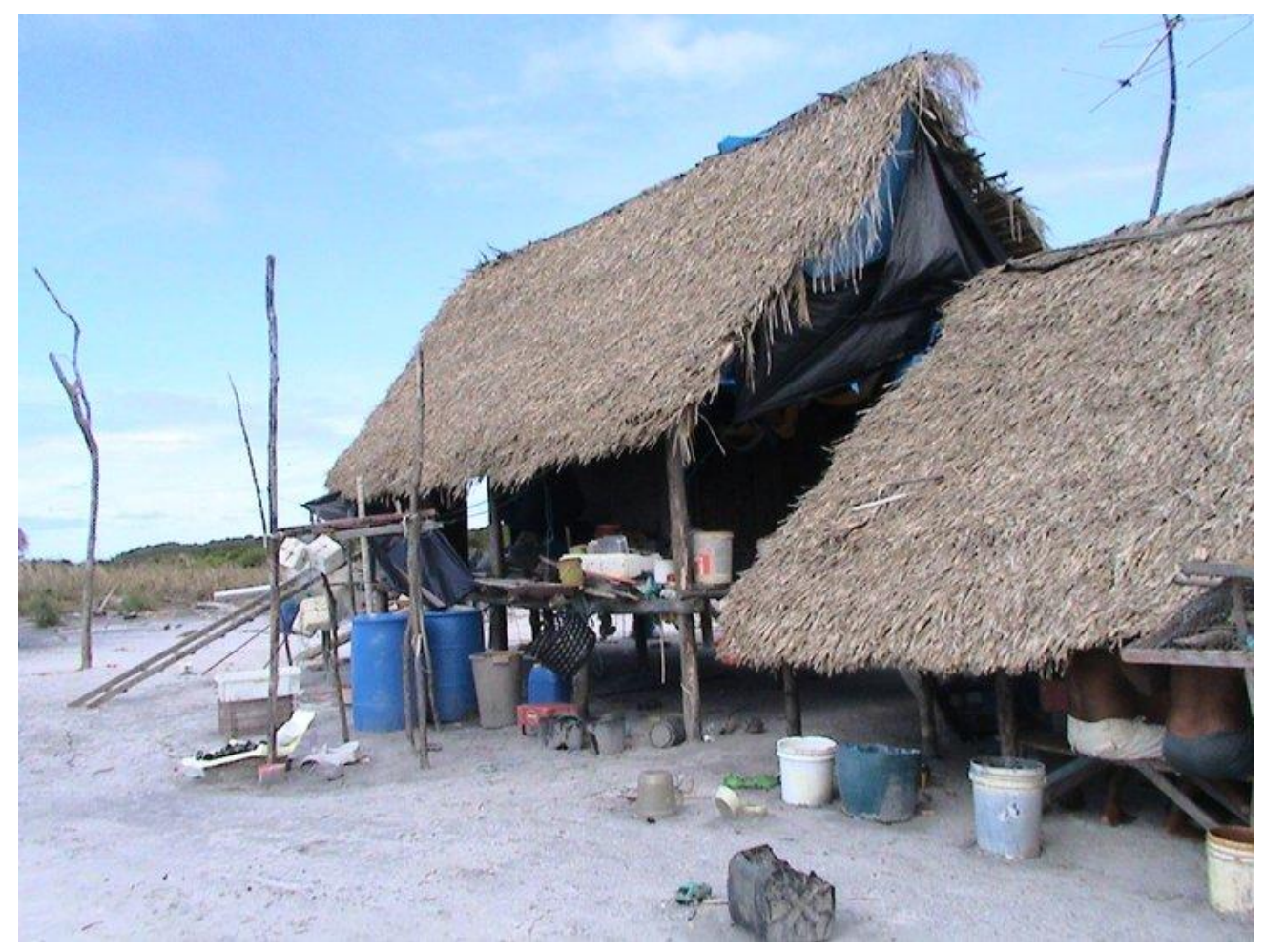

Figura 2: Bem próximo do rancho.

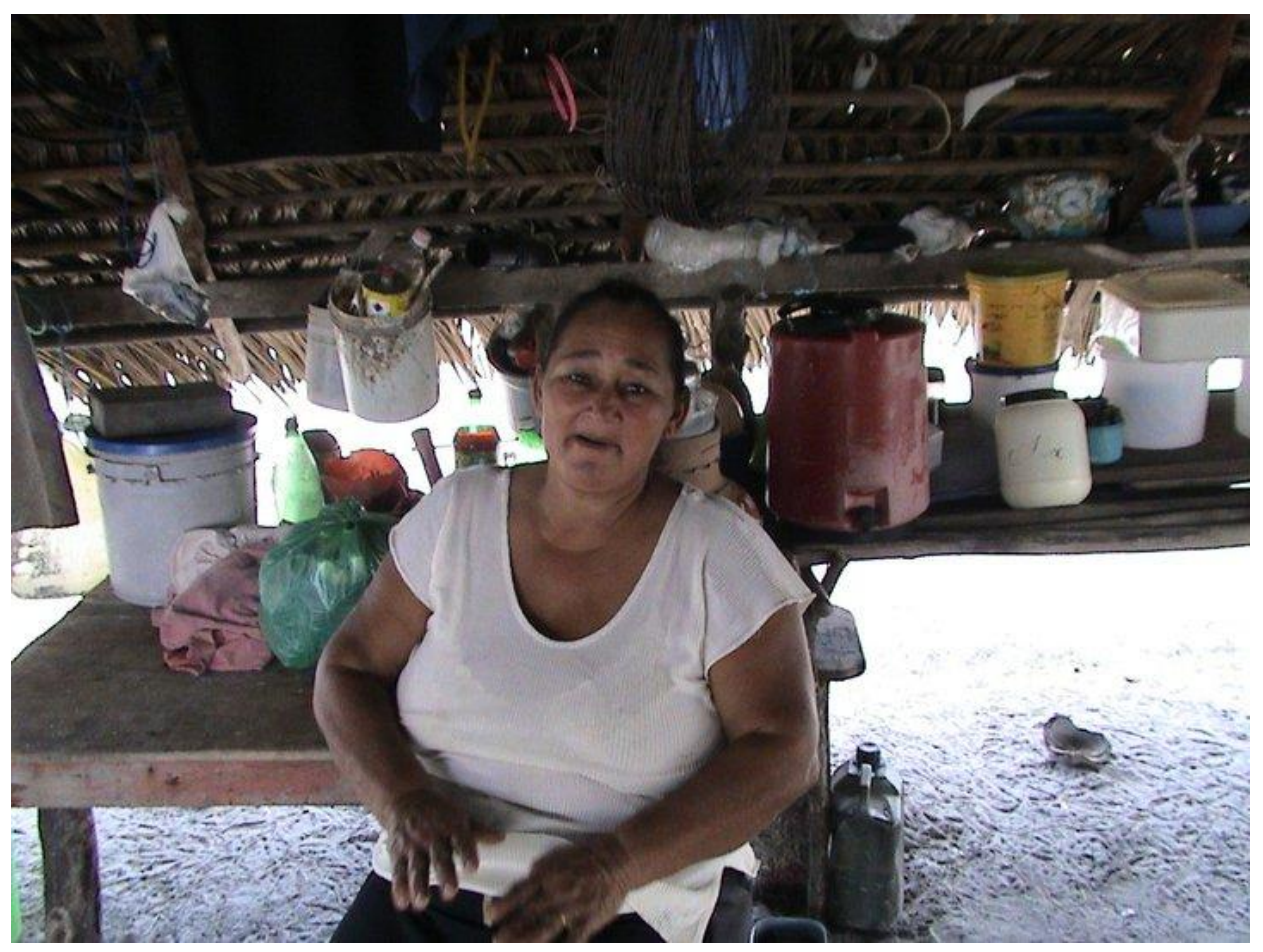

Figura 3: Dona Natividade. 


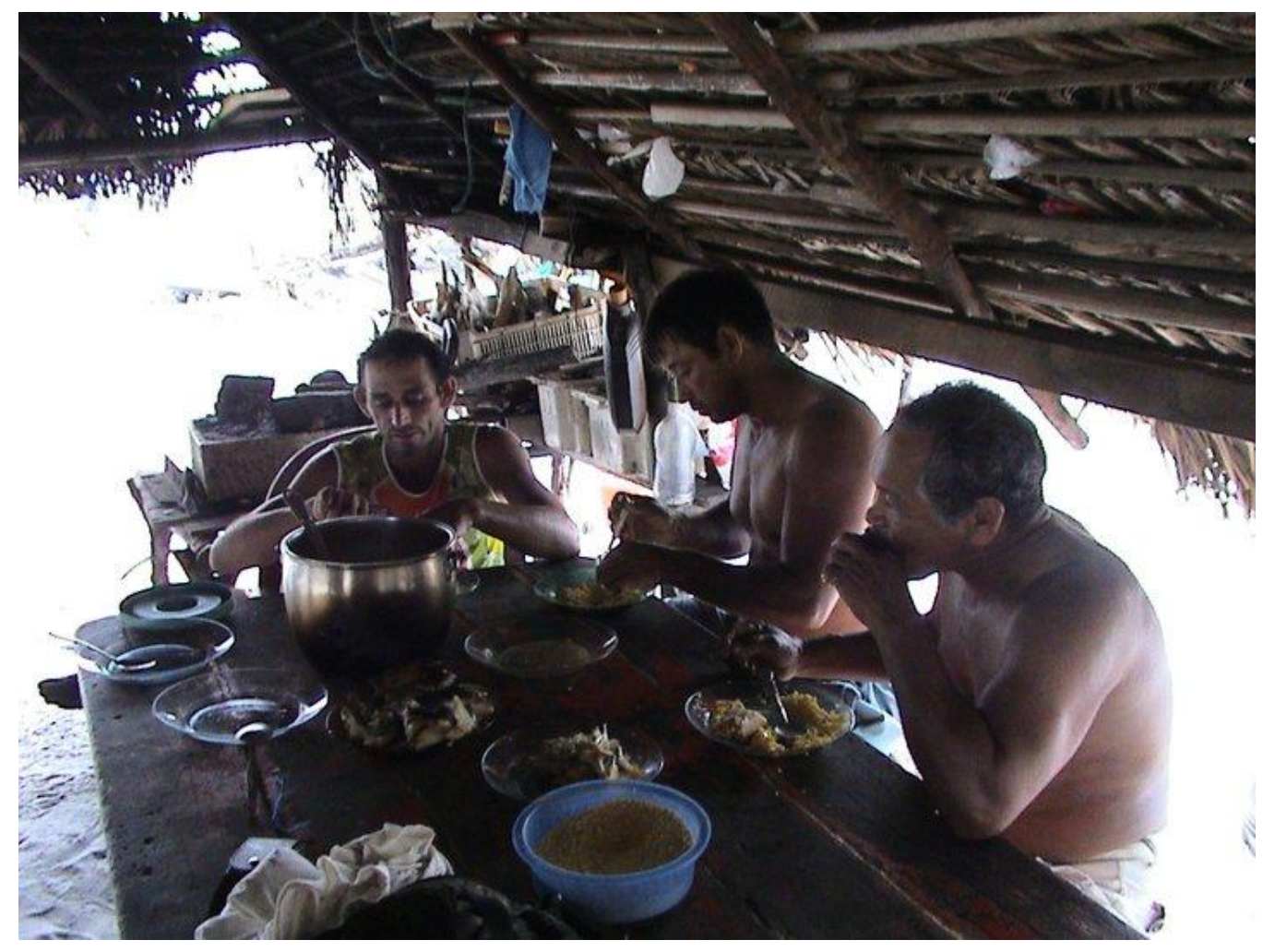

Figura 4: Família reunida para almoço.

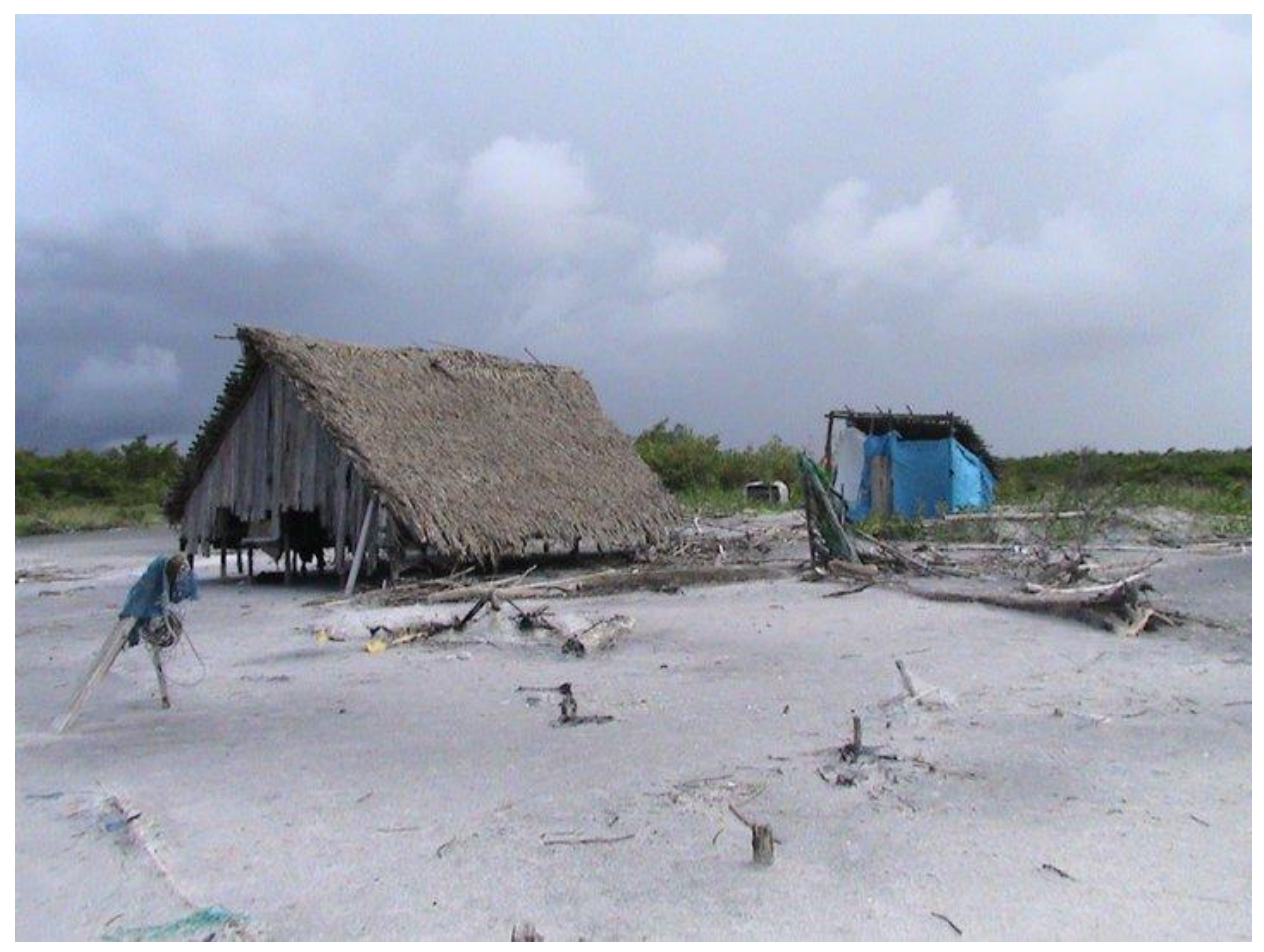

Figura 5: Depósito e latrina. 


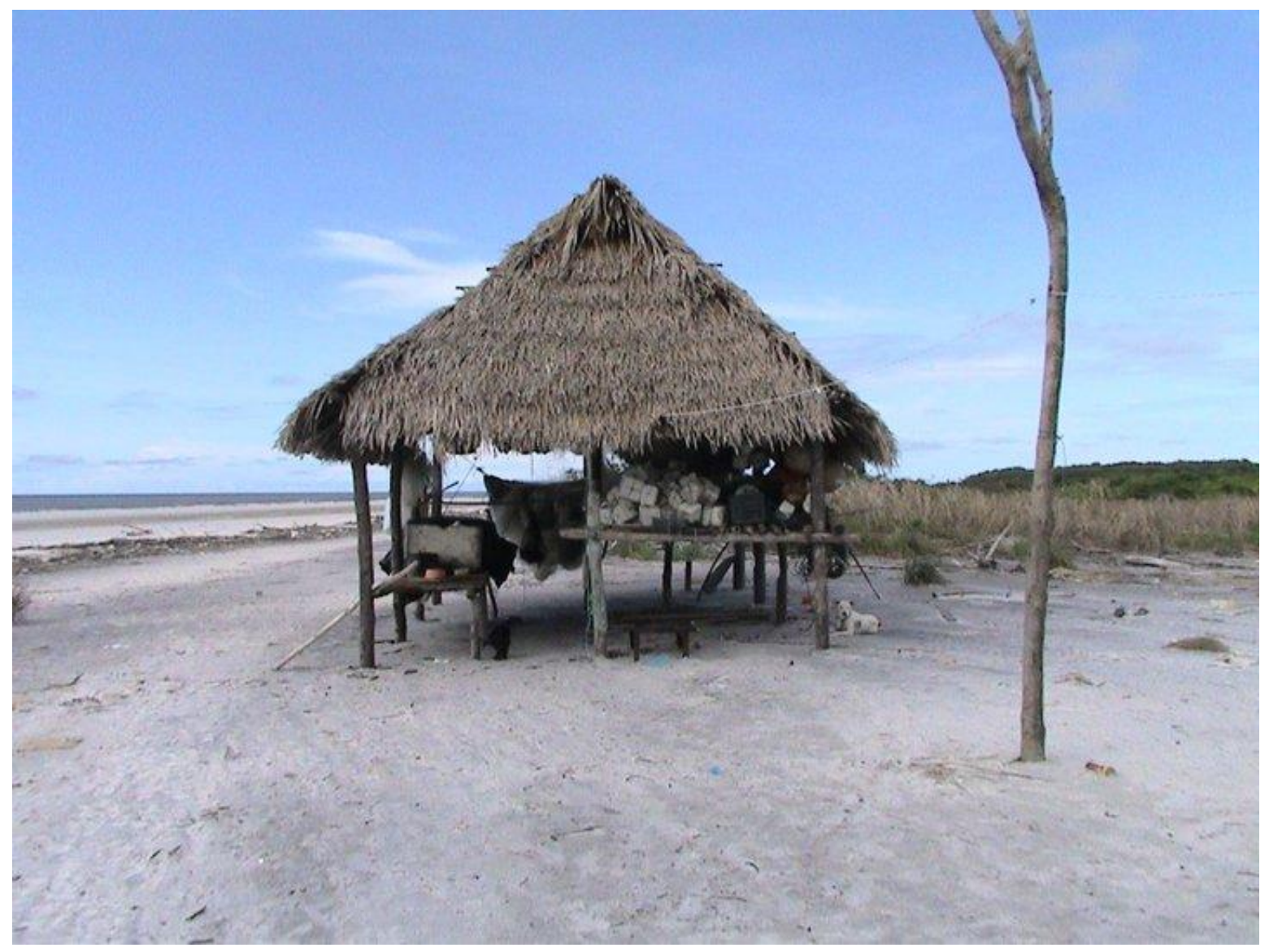

Figura 6: Vista lateral do depósito.

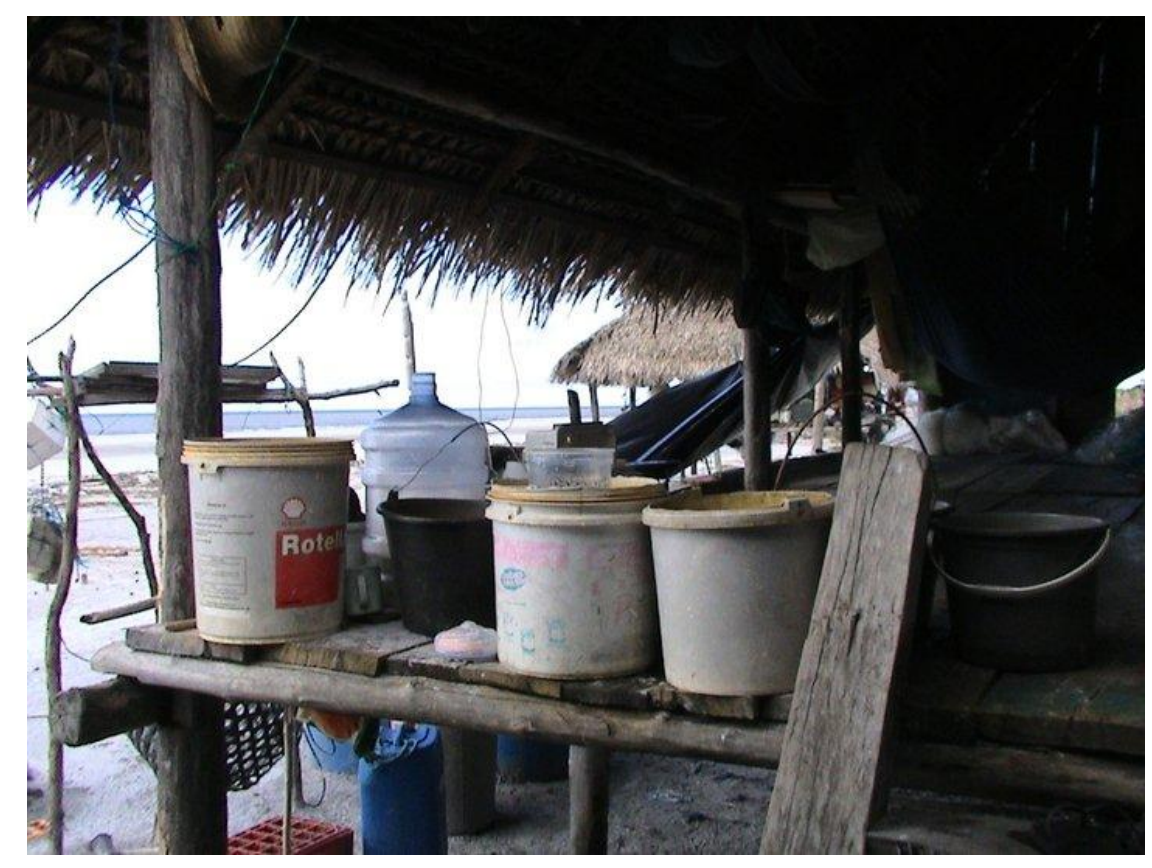

Figura 7: Utensílios domésticos. 


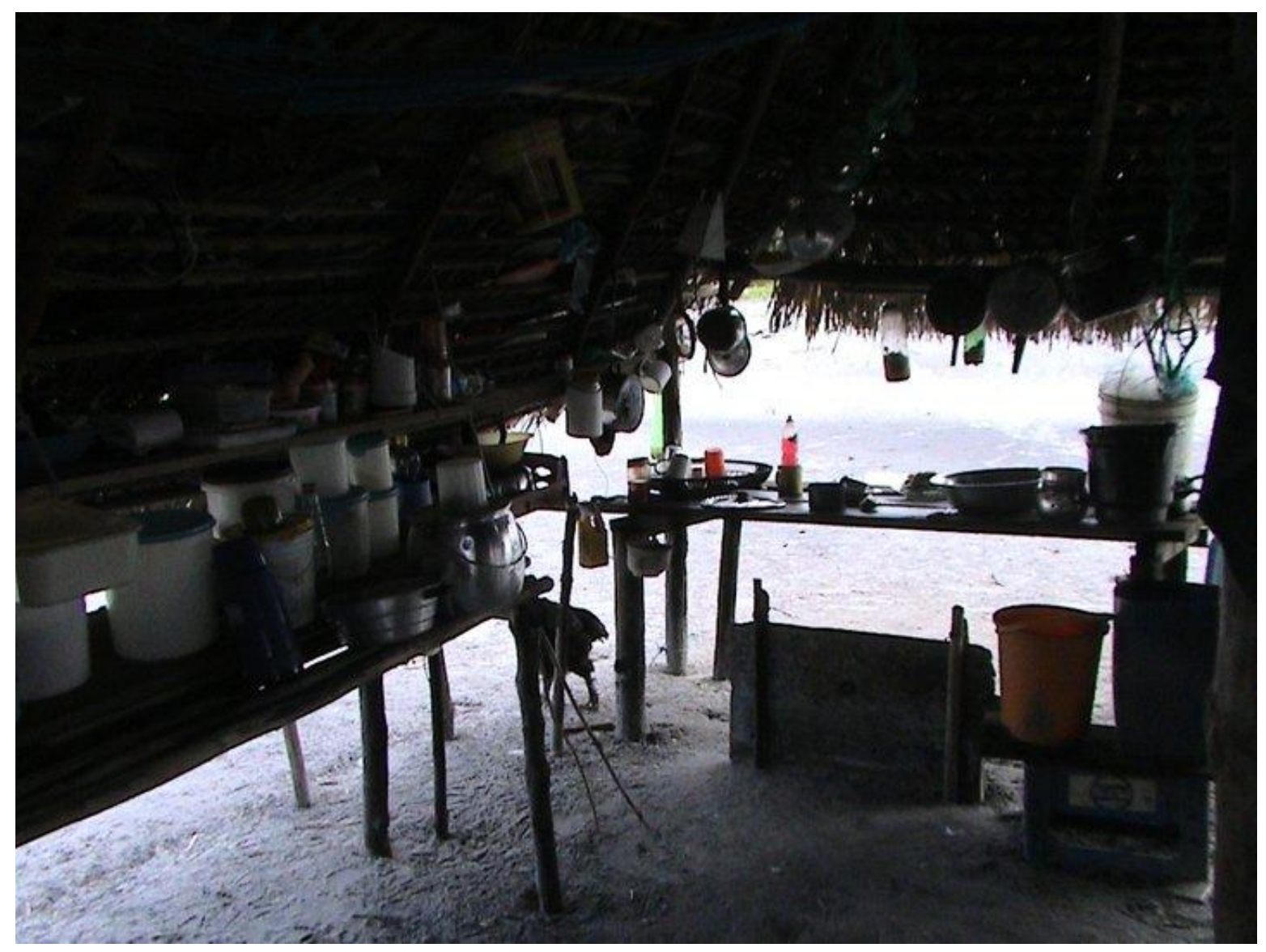

Figura 8: Cozinha. 


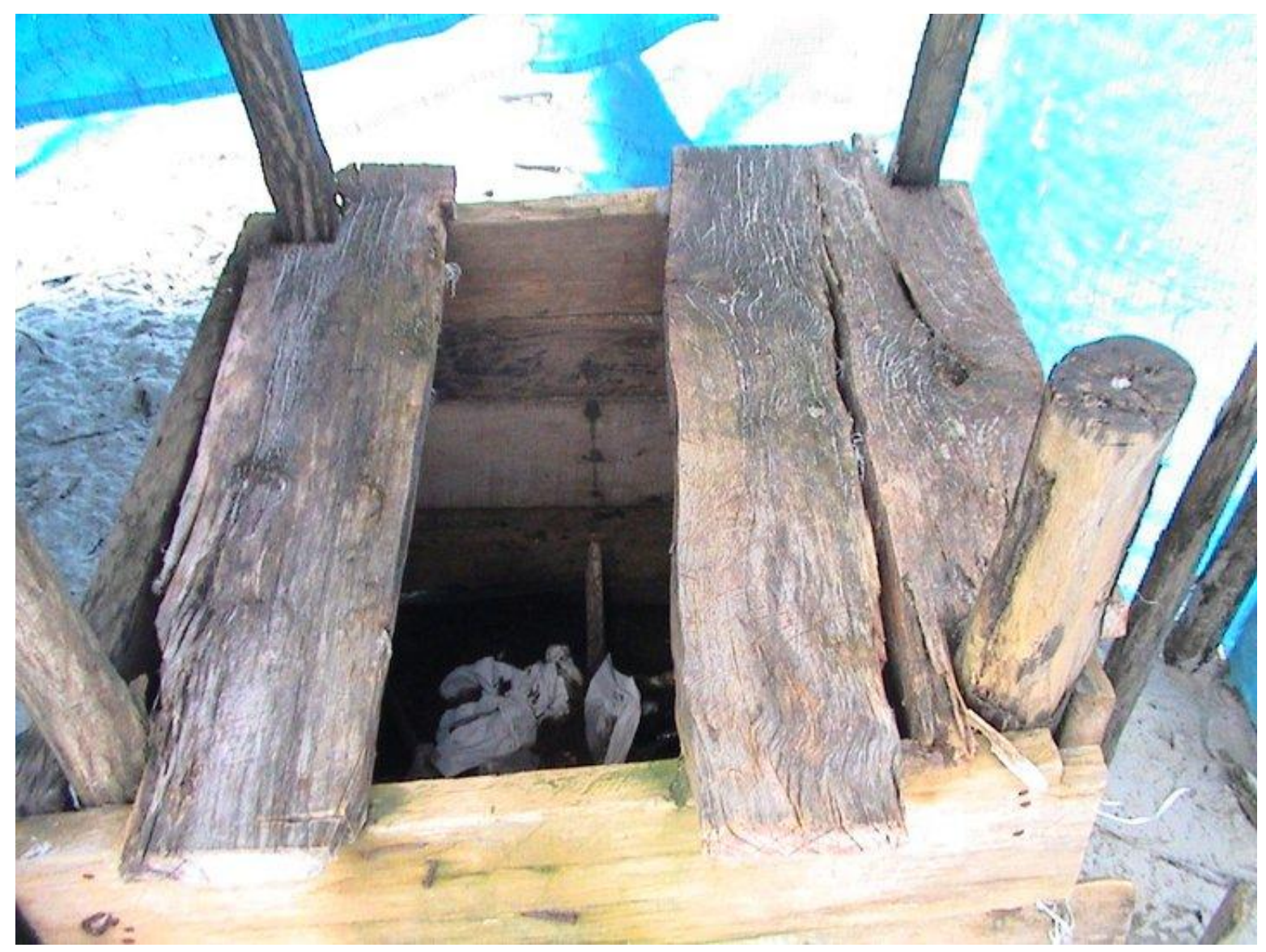

Figura 9: Latrina.

\section{Referências}

LITTLE, Paul E. Territórios Sociais e Povos Tradicionais no Brasil: Por uma antropologia da territorialidade. Brasília: Universidade de Brasília, 2002. 